\title{
Eagle Techniques in Cloud Computational Formulation
}

\author{
Ashish Tiwari, Ritu Garg
}

\begin{abstract}
The eagle expresses of cloud computing plays a pivotal role in the development of technology. In this computing world everyone is active so the end users and providers use various applications which are working as a broker for providing and managing the services. The aim of the paper is to solve the problems in such a way that brokers will provide an optimized solution for cloud service providers and the end users. The key role of allocating the efficient resources by making the algorithm which works for the time and cost optimization keeping in consideration of its quality of services and characteristics. These both are affecting the performance of these techniques is a major drawback due to low accuracy and large computational complexity of the algorithms. As per the scenario, the approach of the research is based on the rough set theory (RST). It's a strategy to found the information revelation and handle the issues like number of parameters (Virtualization, resource sharing, cloud standardization etc). The rough set theory is the new method in cloud service selection so that the best services to provide for cloud users and efficient service improvement for cloud providers.
\end{abstract}

Index Terms: High-Performance computing, Cloud parameters, Cloud brokers, Mathematical model, Cloud simulator.

\section{INTRODUCTION}

Cloud computing is playing the eagle view in the upcoming technology. The Research is going on a vast speed of development in cloud computing. All over the world cloud computing is a big idea in which work is going on. But nowadays cloud computing, providing a lot of practical features for researchers. The researchers are seeing the developing of computational intelligence. The Computational Intelligence makes the stating of the cloud research by the researchers in a rapid way. The "intelligent Systems" are giving the best performance in the field of cloud and IOT by making use of biological and intelligence through nature. In the early days over than new half centuries there are a lot of upcoming technologies in the communication in which computing is becoming an essential equipment of the day today life of the human beings after water, electricity, gas, and telephony. In coming few years it is the vast going technology of the world due to which it becomes very difficult to survive. The heights of computing are increasing day by day. The best suited for the users are the Cloud computing which makes each and every work very easy and suitable [8] [9] [10].

Revised Manuscript Received on July 01, 2019

Ritu Garg, Dept. of Computer Engineering, National Institute of Technology, Kurukshetra, India.

Ashish Tiwari, Dept. of Computer Engineering, National Institute of Technology, Kurukshetra, India

There are a lot of service models which are being completing the cloud services to model the resources. Figure 1 illustrates the approach used models are Software as a Service ( $\mathrm{SaaS})$, Platform as a Service (PaaS) and Infrastructure as a Service (IaaS). In SaaS the utility outfitted to the consumer is to use the organization's applications running on a cloud framework. The bundles area unit out there from totally different emptor devices by suggests that of every a skinny client interface, along with an online program (e.g., net-based email), or associate degree application interface. The client wills nevermore management or management the basic cloud framework along with organize, servers, operating structures, carport, or abundant character utility talents, with the conceivable special case of affected individual actual programming setup settings. Relying at the type of gave ability, there are three circumstances whereby mists area unit utilized: inevitably, there are unit offerings of limit leisure activity to a large reasonably purchasers expedited in cloud frameworks. That's an opportunity to regionally run programs. Associate degree example of this is often the net alternatives of standard restrictive focus programs along with word processors. This circumstance is alluded to as programming program as a provider (saas)[25][32][36].

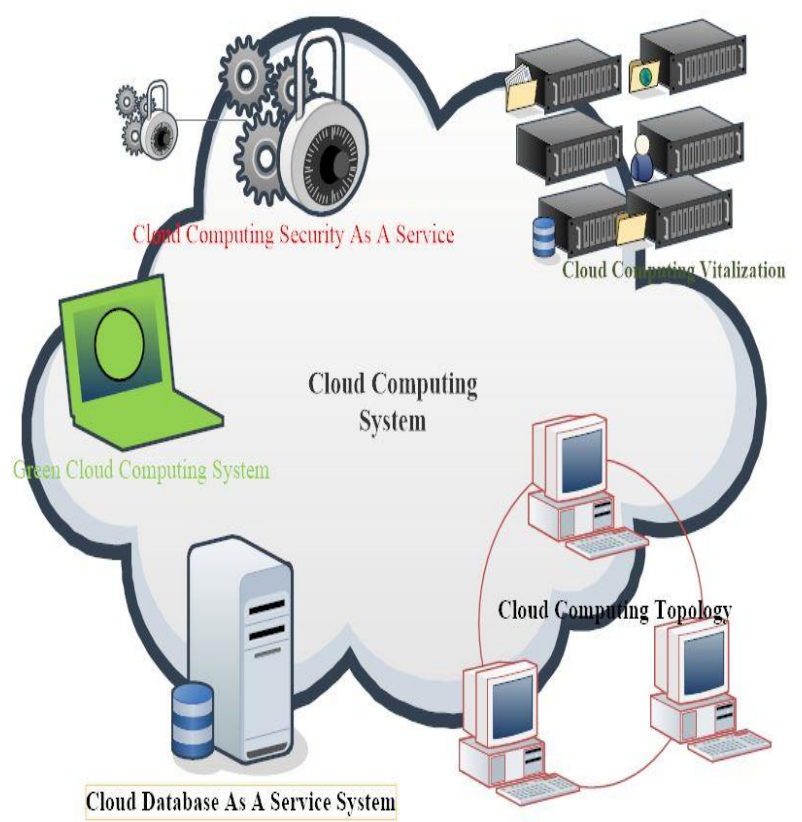

Fig1. Basic Structure of cloud computing System.

In PaaS the utility gave to the supporter is to place in onto the cloud foundation vendee created or no heritable comes created utilizing programming dialects, libraries, administrations, and hardware upheld through manner of the agency. In 
IaaS the capability provided to the client is to arrangement making ready, capacity, systems, and distinctive basic registering resources within which the client will send and run self-assertive programming that will wrap operating frameworks and bundles. Framework affects a massive arrangement of calculation property, that incorporate putt away and handling capability [7] [21] [25] [33]. "A Cloud may be a sort of parallel and assigned convenience like a collection of inter-connected and virtualized computer systems which could be dynamically provisioned and provided joined or larger unified computing resource(s) primarily based wholly on provider-stage agreements." Clouds seem like a mixture of clusters and Grids. Clouds are literally next-era facts facilities with nodes virtualized via hypervisor a technology which incorporates VMs, dynamically provisioned on demand as a tailor-made aid assortment to satisfy a specific provider-stage settlement, that's mounted via a negotiation and approachable as a compostable supplier via net Service technologies inclusive of SOAP and REST [8] [9] [10].

Along with logic, logical thinking, skilled systems, case-based altogether reasoning and symbolic device gaining data of structures, these intelligent algorithms type a part of the sphere of AI (AI). Simply looking at this in depth kind of AI methods, AI will be visible as a combination of diverse studies disciplines, as an example, pc science, bodily structure, philosophy, social science and biology. Five essential paradigms of Computation Intelligence $(\mathrm{CI})$, particularly artificial neural networks (NN), organic process computation (EC), swarm intelligence (SI), artificial immune structures (AIS), and fuzzy structures (FS).

The research paper is divided into seven sections. The first section is dealing with the introduction of cloud computing system. In the second section the background history in the field of computing technology. In the $3^{\text {rd }}$ section literature survey of the cloud computing is done. The next section describes about the problems and issues in the computing field. In the $5^{\text {th }}$ section the parameter factors are being defined on which the broker is working to provide the best services to the end users. The next part is simulating the results and making the matrix in between cloud service providers (CSPs), cloud parameters, end users and datacenters. In the last section the conclusion of overall research paper is done.

\section{BACKGROUND}

In this rapid growing world this technology is going to play a vital role for the researchers and the most suitable for the end users. In the computing actors are performing the work. The computing system deals with the business ways by which the scope is being calculated. It is important to catch fundamental properties of the situation. The growth of its infrastructure is like a speed of light in every fields of the technology is properly shown with the help of figure 2 like servers, virtualizations, database storage systems, security systems and many more which are fulfilling the concept of cloud computing i.e. pay and use model in anywhere, anytime and any service for the end users. The researchers are paying a lot of attention towards this type of technologies. In this environment, users can connect to their resources remotely from the internet. In the Cloud computing growth everything that is done on the environment is somewhere among the cloud. The Vision of Computing is changing rapidly in the form of a utility where providing the services is most important in a larger and faster way. If these services are suitable for the users then they have to pay for it.

Computing services are the most effective working in the applications of computing structures which is being used by end users and providers. There is creation of greenbacks in large scale using solar Microsystems which is very useful to the computing world [3] [4] [5]. The concept of P-P computing is the start point of the computing world. P-P deals with the peer nodes of the computing devices to share the information. It does not follow the rule of client and server. All the nodes are equal and all are client and all are servers according to needs. The main aim of P-P networking to join and operations between nodes, cost and time reduction, scalability and reliability, Proper agreements, Autonomous management of services, dynamic process of working, etc. The age of cluster computing starts with new name by the researchers. According to the researches in early 20th century cluster is connected set of computers to form a large collection. The objective of the cluster computing is to provide virtualization, parallel and distributed system which is connected to the systems. The concept of Grid Computing deals with the highly provided service, trusted services for computer Utilities.

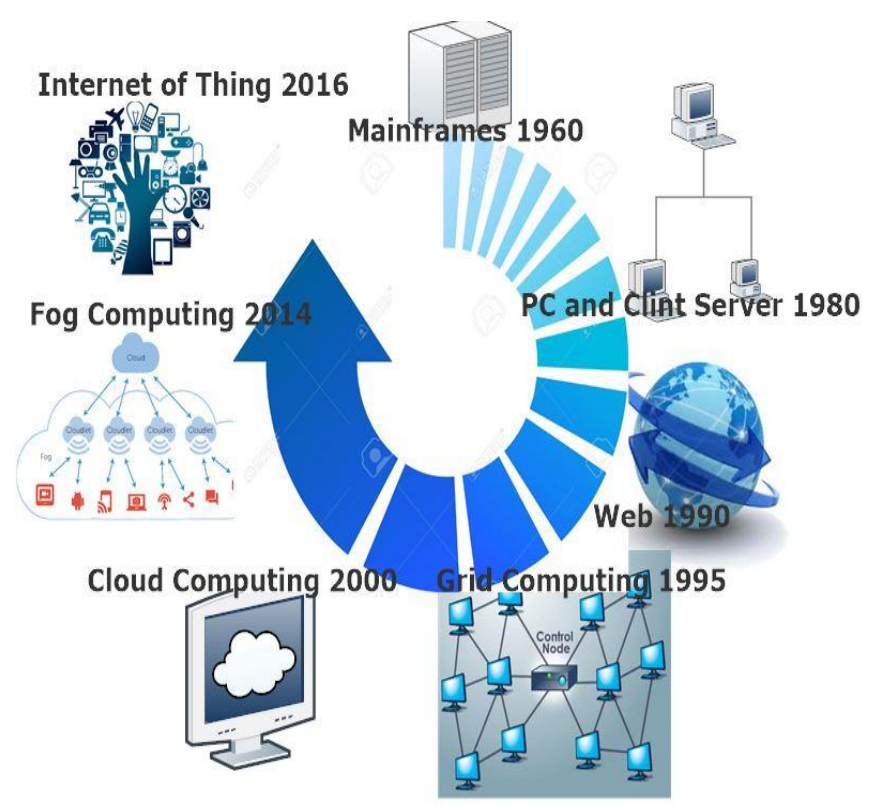

Fig 2. Cloud Computing Journey

According to researchers Grid Computing is the combination of software and hardware that gives consistent access to the end users. Its basic work is to work for parallel and distributed systems that provide the provider to work in sharing, selection and celebration format. The 
major parameters covered by grid computing are Cost, QoS, performance, timing, capabilities, etc. According to few researchers grid is the system where resources are not controlled by the centralized way. It is an open, standard, rule based, nontrivial quality system which provide the services. There are many resources which are managed and provided by the providers [38] [40] [41]. It solves the computational challenges towards task in educational and industrial world. Some researches define the features on the basis of the checklist to provide the best quality resources to the users (Klems et al., 2008). The resources which are doing the computing selection, collaboration and sharing in the world wide systems like supercomputers, resource management, storage management and the devices working in the large scale organizations. The concept of grid is from the electrical grids which are dealing with the computing world to satisfy the conditions such as scalability of information, Easy to the information, security of data, and trust towards the information. The next research and most importance part is the set theory requires trimmings to be either affinity of a set or not. Resembling, binary-valued system requires the tenets of parameters to be either 0 or 1 , encircling showing constraints on the outcome of an inference process. The fuzzy system works on the concept of approximate systems. The role of certainty is very important in the fuzzy logic. Probability also plays an important in creation of fuzzy system [29] [30] [35]. The scheduling is done using any of the above algorithms working. It's a whole method by which the tasks are being performed. The task has to complete successfully. To complete the task successfully anyone needs hardware's and software tools. The things that are affecting the process of scheduling are threads, data flow, networking links, processors, maximization of throughput, minimization of latency, CPU Timing, cost and Quality of Service, SLA according to Quality of Services [16] [17].

\section{LITERATURE SURVEY}

Ants, Bees or Termites - throughout caper insects - show impressive collective problem-solving capabilities. Allow joined up their adjust requesting falsification self-organization, control and rubberiest are abnormal as tag that manufactured frameworks for optimization, control or assignment execution ought to display. Within the amplify decade, distinctive efforts have been made to require social creepy crawlies like an case and create calculations motivated by their entirely self-organized behavior. These approaches bed basically with their rules Swarm Intelligence: It's the form of natural things to the artificial systems. Ants optimization is the start of such algorithms. According to the Azadi Khalili, PSO (particle swarm optimization) working with the hybrid scheduling in cloud computing system. The petulant PSO performs ameliorate compared to Max Min Scheduling and Dumfound Progress era in logic of calendar lightning flash and execution ratio in this study. Bearing in mind the slots in variant nodes had alternative volume of computing possessions; we artful apportion a pursuit deadline into two sub deadlines: map and reduce deadlines. The sub-deadlines were worn for verdict consideration slots to prosecute the tasks of the job. Convulsion, they transformed the DCMRS duty to a substantially -known Minimum Weighted Bipartite Matching (MWBM) problem.

There lot of novel approaches working in the computing world. In the previous days the technology works in the grid and web technologies. While Grid Computing fundamentally helps researchers with computationally costly issues, Cloud Computing tends to the requirements of organizations assembling and sending applications that are of fluctuating scale and multifaceted nature and which use the Web. Albeit back-end innovations might be comparable, the objective gatherings and run of the mill utilize cases for Grids and Clouds are altogether different. The research suggests that the leader makes a framework with accessible cloud computing administrations and elective IT foundation arrangements in the lines and an arrangement of situation criteria in the segments. The research features the contrast between High Performance Computing (HPC) workload and Internet-based administrations workload [12] [13] [14] [29].

\section{PROBLEM STATEMENT}

The major issues which the research deals in computing are the resource cost and the service response time. Asset cost minimization issue and the administration reaction time minimization issue separately. The recreation comes about show that the proposed ideal asset designation strategy can extraordinarily upgrade the execution of mixed media cloud server farm regarding asset cost and administration reaction time. The asset assignment issue in need benefit plan to limit the asset cost and limit the administration reaction time for cloud specialist organizations. The cloud computing dealing the eagle techniques which forms the optimization in timing, cost, scheduling, scalability, security, reliability, Quality of services, availability of services for the end users. From the utilization cases that has been inspected, the research distinguished the accompanying various classes of mission-basic criteria.

- The first technical issue in optimization of computing is the sorting of database in the real time. The commercial parameters dealing with the sorts of uses and administrations can be based on a cloud computing foundation. The Amazon.com site records various utilize cases how organizations are utilizing Amazon Web Services and how these may be sorted.

- The second eagle issue in computing techniques for optimization is scalability. Commercial definition said with regards to Cloud Computing is high responsiveness to differing, capricious request conduct and shorter time to advertise. New businesses have goals that are altogether different from huge private or state-claimed ventures: reasonable, "scale-out" IT framework to develop the business is their significant contention star Cloud.

- The third techniques problem is use of various domains. The systems have the internal and external processes, commercial helper forms, end users faced services. The Research also finds how a Cloud may be utilized to use correspondence and coordinated effort with business accomplices and clients.

- The Fourth issue in computing is SLA (Service 
Level Agreements) move from individual and business information into the Cloud where it is handled and put away should conform to security laws and directions. Legitimate perspectives could likewise make a cloud application more costly because of various security approaches that must be taken after.

The framework can be assessed like an agenda that yields the most reasonable cloud computing administrations and elective IT foundation answers for the situations. From the overall study the researcher comes under the emerging cloud computing concept. Based on this model one of the researcher tries to solve it. Asset Cost Minimization Problem Since various applications regularly have diverse necessities on benefit reaction time, it is trying for cloud suppliers to meet every one of clients' prerequisites with the negligible asset cost. In mixed media cloud, decreasing the administration reaction time can significantly help diminish the conclusion to-end delay. According to research FCFS scheme examine the cloud asset allotment in need benefit conspire in view of the lining model, and give the ideal asset designation to limit the aggregate asset cost and limit the mean administration reaction time [12] [14].

\section{PARAMETER FACTORS}

\section{A. Resource Sharing}

In the start of the computing world grid is formulating the resources on the different ways, but by the start of the concept cloud computing which provides the resources on the basis of demand. Fruitful shared asset get to enables clients to work as though the mutual asset were alone PC [41].

\section{B. Cloud Virtualization}

The idea of virtualization could be very important and historical term used from the day of working system. The idea is being extra delivered in a few fields of computing world. The computing performs a lot of applications in order that its virtualization may be very fundamental [26].

\section{Standardization}

Grids have devoted enormous efforts to arrive standardization both in the consumer interface and in the internal interfaces (for having access to assets), and so reach seamless interoperability. These internal interfaces are stored hidden by the businesses, consequently hampering the interoperability among unique Clouds and the possibility of an international federation of Clouds. So improving current specifications is granted to make sure the required interoperability. For instance, the OGF expertise might be very to accomplish this task [34] [36].

\section{Rough Set}

A rising of intrigued in unpleasant unadulterated arithmetic and its applications may be latterly seen inside the extend of worldwide workshops, conferences and courses that unit of measurement either directly dedicated to harsh sets, encapsulate the subject in their programs, or fair settle for papers that use this approach to resolve issues at hand with the assistance of reasonable figure 3 . An outsized range of prime quality papers on varied aspects of rough sets and their applications are printed in recent years as results of this attention. The speculation has been followed by the event of many code systems that implement rough set operations. The results establish the higher performance of the projected approach. Rough pure mathematics, projected by Pawlak in Eighties as a results of a protracted term program on mathematical elementary analysis of knowledge systems may be seen as a brand new mathematical approach to unclearness (set) and uncertainty (element) [29] [30] [31].

An proportionality connection actuates apportioning of the universe. The segments may be utilized for building the unused subsets of the universe. The Subsets which are most regularly of intrigued have the same esteem of result of qualities. The Fresh set implies whether the element has a place to the set or not, but in a few cases fresh continuously isn't conceivable. In some cases an protest not one or the other has a place to positive nor negatives at that point it is within the boundary. On the off chance that the boundary is non-empty at that point we call it is unpleasant. These are spoken to within the shape of documentations as takes after. Let $\mathrm{A}=(\mathrm{U}, \mathrm{A})$ be an information system and let $\mathrm{B} \leq \mathrm{A}$ and $\mathrm{X}$ $\leq \mathrm{U}$. We can approximate $\mathrm{X}$ using only the information which is determined in B by constructing B-lower and B-upper approximations of $\mathrm{X}$ which is denoted by $\mathrm{BX}$ and $\mathrm{BX}$ respectively where $\mathrm{BX}=\{\mathrm{x} /[\mathrm{x}] \mathrm{B} \leq \mathrm{X}\}$ and $\mathrm{BX}=\{\mathrm{x} /[\mathrm{x}] \mathrm{B} \cap$ $X \neq \varnothing\}$ [29] [30].

The categorization is done by common overview from existing CSP and cloud clients. The coming about set is called as a 'Reduct'. reduct may be a subset of qualities, which could be a transcendent trait set. In this wonder there's choosing haphazardly reduct property set. This relevance generates a threshold value $\gamma \mathbf{i}$ for each attribute out of a scale of 10 .

For each attribute $\rho \mathrm{i}$ the value of

$$
\begin{gathered}
\rho \gamma \mathrm{i} \geq 1 \text { or TRUE } \\
\text { 0, Otherwise }
\end{gathered}
$$

\section{0 , Otherwise}$$
\{
$$

The start of the computing world grid is formulating the resources on the different ways, but by the start of the concept cloud computing which provides the resources on the basis of demand. Fruitful shared asset get to enables clients to work as though the mutual asset were alone PC [29] [30]. In this inquire about work we have been designating the employments to the benefit suppliers based on the $\delta$ esteem. This appeared the CSP and its Fluffy taken a toll values. The fluffy fetched of the benefit supplier is the whole of all the enrollment values of each quality as per the equation 2 .

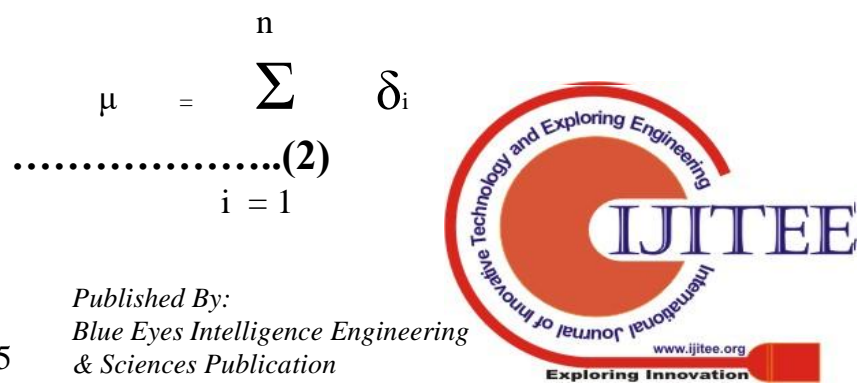




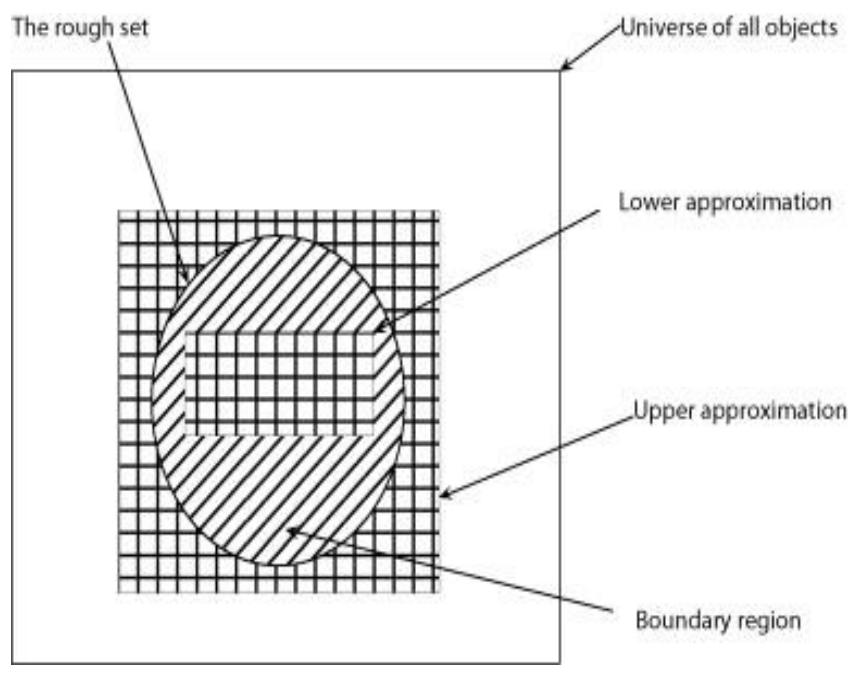

Fig 3. Rough Set Theory in Cloud Computing

The difficult set theory is established on the idea that with each object of the universe of discourse we partner some know-how (or capabilities). For instance, if objects are patients suffering from a certain disorder, signs of the disorder kind knowledge about sufferers. Objects characterized by using the identical understanding are indiscernible (or equivalent) in view of the on-hand knowledge about them. Therefore, hard set idea expresses vagueness not by way of membership, but with the aid of employing a boundary neighborhood of a set. The theory is one of a kind of, and complementary to, fuzzy sets. The suggestion of a hard set includes approximation of a suite by means of a pair of two crisp units called the lower and higher approximations of the set. The motivation for hard set conception has come from the ought to symbolize subsets of a universe in terms of equivalence classes of a clustering of the universe [29] [30].

\section{SIMULATIONS AND RESULTS}

The simulation of the results field unit being created exploitation Google AppEngine is also a platform for setting up ascendable internet applications which may be run on excessive of server forming the surroundings. It provides a group of arthropod genus associate degreed a software model that enables developers to require knowledge of further services furnished by means of Google like Mail, information retailer, buffer store, and others. These functions are run inside of a sandbox and AppEngine can watch out for robotically scaling as soon as required. The CloudSim toolkit supports each and every approach and behavior modeling of Cloud approach elements like skills centers, virtual machines (VMs) and useful resource provisioning policies. The satisfactory of CloudSim is incontestable via a case learn involving dynamic provisioning of software offerings within the hybrid federate clouds surroundings. The outcome of this case gain knowledge of proves that the federate Cloud computing mannequin substantially improves the applying QoS necessities underneath unsteady useful resource and restores demand patterns. The data sets which are taken are explained in the Figure 4,5,6,7 in the form of tables [36] [37]. The core rate of Aneka could also be a provider directed runtime surroundings. Code as a carrier solutions field unit at the perfect concludes of the Cloud computing stack and those they present finish customers with accomplice measure built-in carrier comprising hardware, development systems, and applications. Customers do not appear to be allowed to customize the provider however get access to a selected application hosted within the Cloud.

\begin{tabular}{|c|c|c|c|c|c|c|}
\hline & \multicolumn{6}{|c|}{ Cloud Users } \\
\hline \multirow{5}{*}{ Parameters } & & 5 & 10 & 15 & 20 & 25 \\
\hline & 4 & 0.502 & 0.628213 & 0.729 & 0.786 & 1.35 \\
\hline & 6 & 0.557 & 0.7405 & 1.008 & 1.258 & 1.292 \\
\hline & 8 & 0.709 & 0.7924 & 0.86444 & 1.401 & 2.823 \\
\hline & 10 & 0.4001 & 1.01 & 1.36 & 1.81 & 3.056 \\
\hline \multicolumn{7}{|l|}{2 CSPs } \\
\hline 10 Datacenters & & & & & & \\
\hline
\end{tabular}

Fig 4. Data Matrix for Evaluation of CPU Performance between End Users and Parameters

\begin{tabular}{|c|c|c|c|c|c|c|}
\hline CPU UTILIZATION & \multicolumn{6}{|c|}{ Cloud PARAMETERS } \\
\hline \multirow{5}{*}{ DATACENTERS } & & 4 & 6 & 8 & 10 & 12 \\
\hline & 5 & 0.7418 & 0.755 & 0.8655 & 0.9765 & 1.42 \\
\hline & 10 & 0.5343 & 0.644 & 0.7554 & 0.876 & 1.32 \\
\hline & 15 & 0.4554 & 0.45645 & 0.6544 & 0.7543 & 1.22 \\
\hline & 20 & 0.4001 & 0.4223 & 0.4554 & 0.5444 & 1 \\
\hline 2 CSPs & & & & & & \\
\hline 5 Users & & & & & & \\
\hline
\end{tabular}

Fig 5. Data Matrix for Evaluation of CPU Performance between Datacenters and Parameters

\begin{tabular}{|c|c|c|c|c|c|c|}
\hline & \multicolumn{6}{|c|}{ Cloud users } \\
\hline \multirow{5}{*}{ Parameters } & & 5 & 10 & 15 & 20 & 25 \\
\hline & 4 & 384.5 & 385.5 & 388 & 410.75 & 413.25 \\
\hline & 6 & 350.5 & 396.75 & 406.75 & 419 & 438.25 \\
\hline & 8 & 332.75 & 376 & 396.75 & 403.75 & 461.25 \\
\hline & 10 & 300.5 & 316.25 & 418.25 & 508.5 & 551.25 \\
\hline
\end{tabular}

2 CSPS

10 Datacenters

Fig 6. Data Matrix for Evaluation of efficient time Evaluation between End Users and Parameters

\begin{tabular}{|c|c|c|c|c|c|c|}
\hline & \multicolumn{6}{|c|}{ Cloud PARAMETERS } \\
\hline \multirow{5}{*}{ DATACENTERS } & & 4 & 6 & 8 & 10 & 12 \\
\hline & 5 & 1310 & 1259 & 562 & 531 & 530 \\
\hline & 10 & 1176 & 1168 & 570 & 570 & 565 \\
\hline & 15 & 1124 & 1100 & 498 & 543 & 542 \\
\hline & 20 & 1115 & 1102 & 480 & 475 & 325 \\
\hline
\end{tabular}

2 CSPS

5 Users

Fig 7. Data Matrix for

Published By:

Blue Eyes Intelligence Engineering

\& Sciences Publication 
Evaluation of efficient time Evaluation between Datacenters and Parameters

Aneka is a software platform and a framework for developing distributed applications on the Cloud. It harnesses the computing resources of a heterogeneous network of desktop PCs and servers or datacenters on demand. Aneka provides developers with a rich set of APIs for transparently exploiting such resources and expressing the logic of applications by using a variety of programming abstractions is shown with the help of Figures 8, 9, 10, 11.

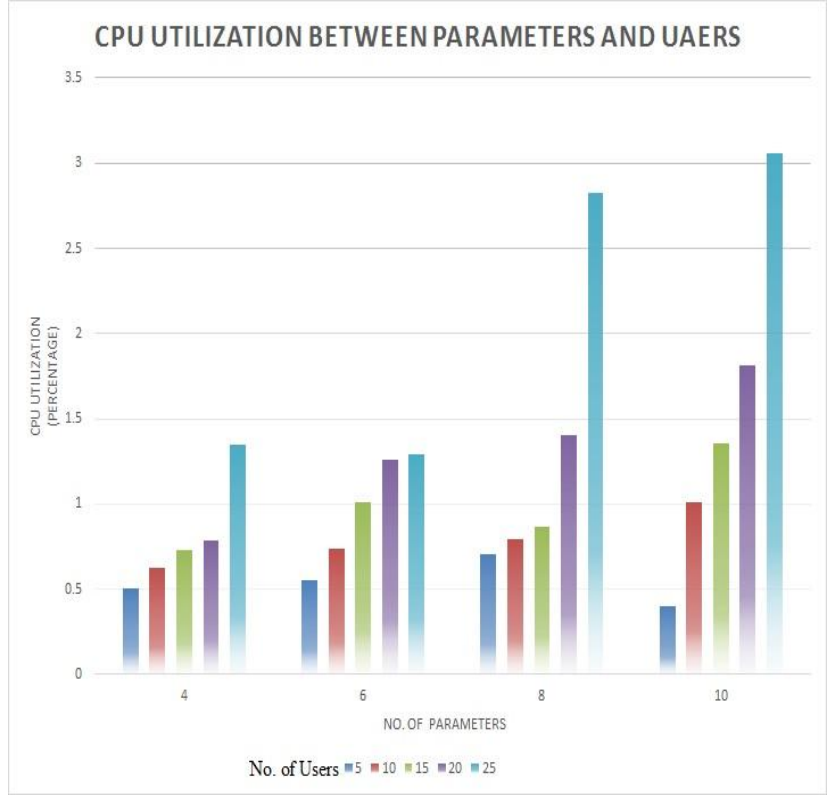

Fig 8. Graph Showing Evaluation of CPU performance between End Users and Parameters

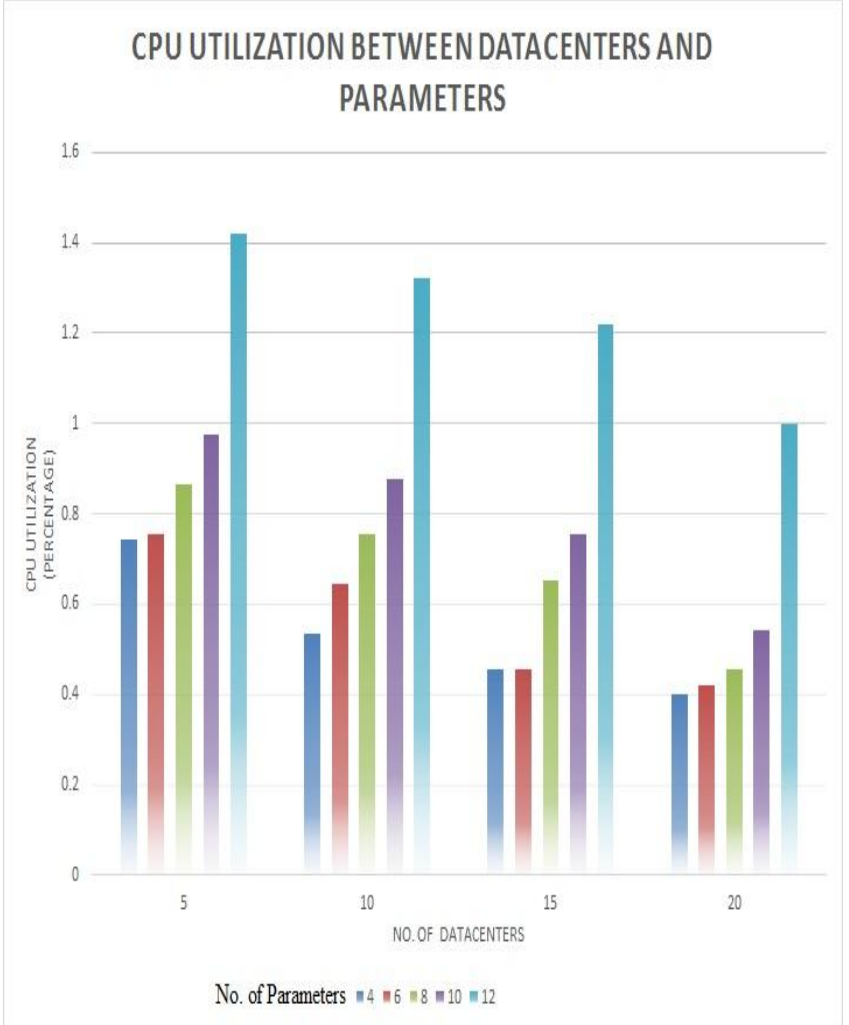
between Datacenters and Parameters

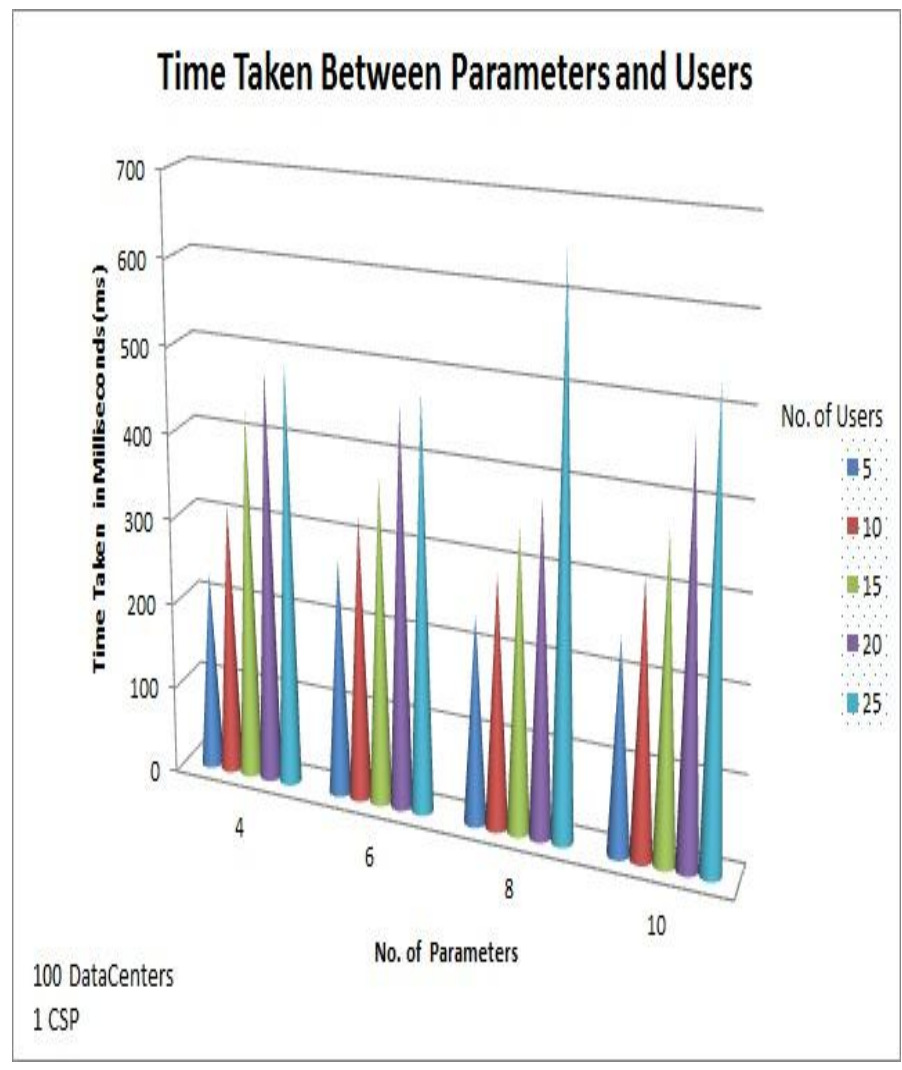

Fig 10. Graph Showing Evaluation of efficient time Evaluation between End Users and Parameters

\section{TIME TAKEN BETWEEN DATACENTERS AND PARAMETERS}

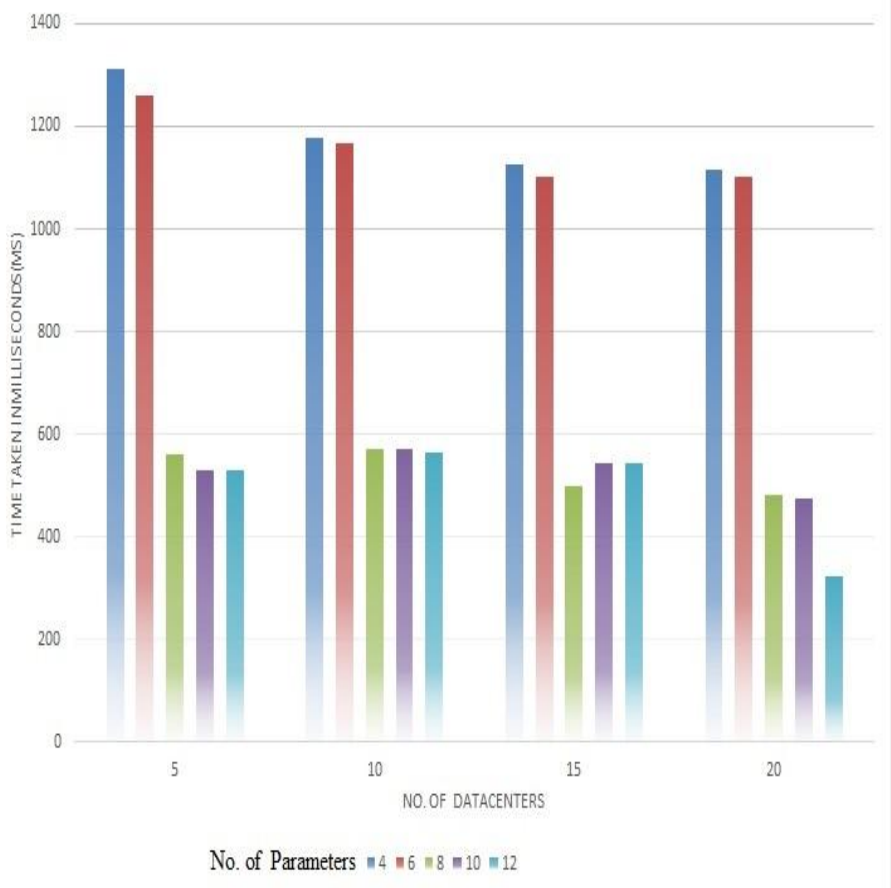

Fig 11. Graph Showing Evaluation of efficient time Evaluation between

Published By: 


\section{Datacenters and Parameters}

\section{CONCLUSION}

Cloud computing is additionally a modern and promising worldview advertising IT administrations as computing utilities. As Clouds rectangular degree planned to supply administrations to outside clients, providers bought to be salaried for sharing their assets and capabilities. The progressive cloud technologies have kept back for market-oriented asset management which they bought to be increased to assist: arrangement of QoS between clients and providers to look at SLAs. As Clouds rectangular degree rising as subsequent-new discharge information centers and purposeful to help present service-oriented capacities, it can be pivotal that they're planned to be vigor competitively estimated to decrease each their vigor charge and carbon impression on the environment. To reap this at application method systems level, we would like to investigate new systems for allocation of resources to purposes depending on great of service expectations of users and repair contracts founded between purchasers and suppliers. In the end, QoS and SLA social manage additionally can be important earlier than ICT businesses attain high levels of self assurance inside the Cloud. The preliminary problems regarding the experiments carried out exhibit that the amazing use of Cloud assets is obviously primary and a alternate-offs between price and performance need to be carefully evaluated. To scale back the price of know-how placement for time-varying employment purposes, builders must optimally make the most the worth distinction between storage and network offerings across a couple of CSPs. To achieve this intention, we have a tendency to designed algorithms with full and partial future employment information. Further elaborated system for the period of this course will definitely characterize subsequent step from this work.

\section{REFERENCES}

1. Abawajy, J. (2009, December). Determining service trustworthiness in Intercloud computing environments. In Pervasive Systems, Algorithms, and Networks (ISPAN), 2009 10th International Symposium on (pp. 784-788). IEEE.

2. Abawajy, J. H., \& Dandamudi, S. P. (2003, December). Parallel job scheduling on multicluster computing systems. In null (p. 11). IEEE.

3. Almuttairi, R. M., Wankar, R., Negi, A., Rao, C. R., Agarwal, A., \& Buyya, R. (2013). A two phased service oriented Broker for replica selection in data grids. Future Generation Computer Systems, 29(4), 953-972.

4. A., Abawajy, J., \& Buyya, R. (2012). Energy-aware resource allocation heuristics for efficient management of data centers for cloud computing. Future generation computer systems, 28(5), 755-768.

5. Bera, S., Misra, S., \& Rodrigues, J. J. (2015). Cloud computing applications for smart grid: A survey. IEEE Transactions on Parallel \& Distributed Systems, (5), 1477-1494.

6. Bonabeau, E., Marco, D. D. R. D. F., Dorigo, M., Théraulaz, G., \& Theraulaz, G. (1999). Swarm intelligence: from natural to artificial systems (No. 1). Oxford university press.

7. Buyya, R. (2010, October). Cloud computing: The next revolution in information technology. In Parallel Distributed and Grid Computing (PDGC), 2010 1st International Conference on (pp. 2-3). IEEE.

8. Buyya, R., Beloglazov, A., \& Abawajy, J. (2010). Energy-efficient management of data center resources for cloud computing: a vision, architectural elements, and open challenges. arXiv preprint arXiv:1006.0308.
9. Buyya, R., Broberg, J., \& Goscinski, A. M. (Eds.). (2010). Cloud computing: Principles and paradigms (Vol. 87). John Wiley \& Sons.

10. Buyya, R., Yeo, C. S., Venugopal, S., Broberg, J., \& Brandic, I. (2009). Cloud computing and emerging IT platforms: Vision, hype, and reality for delivering computing as the 5th utility. Future Generation computer systems, 25(6), 599-616.

11. Calheiros, R. N., Ranjan, R., Beloglazov, A., De Rose, C. A., \& Buyya, R. (2011). CloudSim: a toolkit for modeling and simulation of cloud computing environments and evaluation of resource provisioning algorithms. Software: Practice and experience, 41(1), 23-50.

12. Chandrasekar, R., \& Misra, S. (2006, December). Introducing an ACO based paradigm for detecting wildfires using wireless sensor networks. In Ad Hoc and Ubiquitous Computing, 2006. ISAUHC'06. International Symposium on (pp. 112-117). IEEE.

13. Chen, F., Guo, K., Lin, J., \& La Porta, T. (2012, March). Intra-cloud lightning: Building CDNs in the cloud. In INFOCOM, 2012 Proceedings IEEE (pp. 433-441). IEEE.

14. Deepa, O., \& Senthilkumar, A. (2016). Swarm intelligence from natural to artificial systems: Ant colony optimization. Networks (GRAPH-HOC), 8(1).

15. F. Mann(2009), Cloud Computing: The Next Revolution in IT, Photogrammetric Week '09.

16. Foster, I., \& Kesselman, C. (Eds.). (2003). The Grid 2: Blueprint for a new computing infrastructure. Elsevier.

17. Geeta, C. M., Raghavendra, S., Buyya, R., Venugopal, K. R., Iyengar, S S., \& Patnaik, L. M. (2018). Data Auditing and Security in Cloud Computing: Issues, Challenges and Future Directions. International Journal of Computer (IJC), 28(1), 8-57.

18. Garg, R., \& Singh, A. K. (2011). Fault tolerance in grid computing: state of the art and open issues. International Journal of Computer Science \& Engineering Survey (IJCSES), 2(1), 88-97.

19. Garg, R., \& Singh, A. K. (2015). Adaptive workflow scheduling in grid computing based on dynamic resource availability. Engineering Science and Technology, an International Journal, 18(2), 256-269.

20. Garg, R., \& Singh, A. K. (2013). Enhancing the discrete particle swarm optimization based workflow grid scheduling using hierarchical structure. International Journal of Computer Network and Information Security, 5(6), 18

21. Garg, R., \& Singh, A. K. (2011). Multi-objective optimization to workflow grid scheduling using reference point based evolutionary algorithm. International Journal of Computer Applications, 22(6), 44-49.

22. Gupta, A., \& Garg, R. (2017, September). Load balancing based task scheduling with ACO in cloud computing. In 2017 International Conference on Computer and Applications (ICCA) (pp. 174-179) IEEE.

23. Herawan, T., Deris, M. M., \& Abawajy, J. H. (2010). A rough set approach for selecting clustering attribute. Knowledge-Based Systems, 23(3), 220-231.

24. Mansouri, Y., Toosi, A. N., \& Buyya, R. (2017). Cost optimization for dynamic replication and migration of data in cloud data centers. IEEE Transactions on Cloud Computing.

25. Mell, P., \& Grance, T. (2011). The NIST definition of cloud computing.

26. Mosleh, M. A., Radhamani, G., Hazber, M. A., \& Hasan, S. H. (2016) Adaptive Cost-Based Task Scheduling in Cloud Environment. Scientific Programming, 2016.

27. Nan, X., He, Y., \& Guan, L. (2011, October). Optimal resource allocation for multimedia cloud based on queuing model. In Multimedia signal processing (MMSP), 2011 IEEE 13th international workshop on (pp. 1-6). IEEE.

28. Nan, X., He, Y., \& Guan, L. (2012, May). Optimal resource allocation for multimedia cloud in priority service scheme. In Circuits and systems (ISCAS), 2012 IEEE international symposium on (pp. 1111-1114). IEEE.

29. Naga, K. P. P., Kodialam, M., \& Varvello, M. (2014). U.S. Patent Application No. 13/597,614.

30. Pawlak, Z. (1982). Rough sets. International journal of computer \& information sciences, 11(5), 341-356.

31. Sundareswaran, S., Squicciarini, A., \& Lin, D. (2012, June). A brokerage-based approach for cloud service selection. In Cloud computing (cloud), 2012 ieee 5th international conference on (pp 558-565). IEEE.

32. Tiwari, A., \& Sharma, R. M. (2016, August). Potent Cloud Services Utilization with Efficient Revised Rough Set Optimization Service 
Parameters. In Proceedings of the International Conference on Advances in Information Communication Technology I\& Computing (p. 90). ACM.

33. Tiwari, A., Mahrishi, M., \& Fatehpuria, S. A Broking Structure Originated on Service accommodative Using MROSP Algorithm.

34. Tiwari, A., Nagaraju, A., \& Mahrishi, M. (2013, February). An optimized scheduling algorithm for cloud broker using adaptive cost model. In Advance Computing Conference (IACC), 2013 IEEE 3rd International (pp. 28-33). IEEE.

35. Tiwari, A., Sah, M. K., \& Gupta, S. (2015). Efficient Service Utilization in Cloud Computing Exploitation Victimization as Revised Rough Set Optimization Service Parameters. Procedia Computer Science, 70, 610-617.

36. Tiwari, A., Sah, M. K., \& Malhotra, A. (2015, September). Effective service Utilization in Cloud Computing exploitation victimisation rough pure mathematics as revised ROSP. In Reliability, Infocom Technologies and Optimization (ICRITO)(Trends and Future Directions), 2015 4th International Conference on (pp. 1-6). IEEE.

37. Tiwari, A., Sharma, V., \& Mahrishi, M. (2014). Service Adaptive Broking Mechanism Using MROSP Algorithm. In Advanced Computing, Networking and Informatics-Volume 2 (pp. 383-391). Springer, Cham.

38. Tiwari, A., Tiwari, A. K., Saini, H. C., Sharma, A. K., \& Yadav, A. K (2013). A Cloud Computing using Rough set Theory for Cloud Service Parameters through Ontology in Cloud Simulator. In ACITY-2013 Conference at Chennai, in CS and IT proceedings.

39. Tiwari, A., Tiwari, A. K., Saini, H. C., Sharma, A. K., \& Yadav, A. K. (2013). A Cloud Computing using Rough set Theory for Cloud Service Parameters through Ontology in Cloud Simulator. In ACITY-2013 Conference at Chennai, in CS and IT proceedings.

40. Vallverdú, J., Talanov, M., \& Khasianov, A. (2017). Swarm Intelligence via the Internet of Things and the Phenomenological Turn. Philosophies, 2(3), 19.

41. Vaquero, L. M., Rodero-Merino, L., Caceres, J., \& Lindner, M. (2008). A break in the clouds: towards a cloud definition. ACM SIGCOMM Computer Communication Review, 39(1), 50-55.

42. Vecchiola, C., Pandey, S., \& Buyya, R. (2009, December). High-performance cloud computing: A view of scientific applications. In Pervasive Systems, Algorithms, and Networks (ISPAN), 2009 10th International Symposium on (pp. 4-16). IEEE.

43. Zhang, L., Wu, C., Li, Z., Guo, C., Chen, M., \& Lau, F. C. (2013). Moving big data to the cloud: An online cost-minimizing approach. IEEE Journal on Selected Areas in Communications, 31(12), 2710-2721.

44. Zhou, Z., Abawajy, J., Chowdhury, M., Hu, Z., Li, K., Cheng, H., ... \& Li, F. (2017). Minimizing SLA violation and power consumption in Cloud data centers using adaptive energy-aware algorithms. Future Generation Computer Systems.

\section{AUTHORS PROFILE}

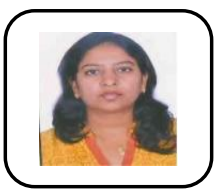

Dr. Ritu Garg had done PhD (NIT Kurukshetra)2016, M.Tech(M.M.E.C, Mullana) 2006, B.Tech(B.C.E.T, Gurdaspur)2001. Area of research is Resource management in Grid/Cloud Computing, Evolutionary Computing, Internet of things, Energy Harvesting, security of IOT etc. Madam had been published several research papers in the international and nation levels. For more details go thought the given link on google scholar https://scholar.google.co.in/citations?user=bG5ujbQAAAAJ\&hl=en

On Reseach Gate

https://www.researchgate.net/profile/Garg_Ritu.

Ashish Tiwari, Ph.D. Research Scholar, NIT Kurukshetra Haryana KURUKSHETRA, Haryana 136119, INDIA

Pursuing Ph.D. from NIT Kurukshetra since January Pursuing Ph.D. from NIT Kurukshetra since January
2016, at Haryana(India) I have done M.Tech. in computer science and engineering from the Central University of Rajasthan in the year of 2013, B.Tech in 2010. Myself Member of International Associations of
Engineers(IAENG) dated 20th November 2017. For more details go thought the given link on google scholar https://scholar.google.co.in/citations?user=dCaTOoUAAAAJ\&hl=en 